\title{
Hospitalisation for COPD in Puglia: the role of hospital discharge database to estimate prevalence and incidence
}

\author{
P. Trerotoli1, N. Bartolomeo1, A.M. Moretti2, G. Serio1
}

ABSTRACT: Hospitalisation for COPD in Puglia: the role of hospital discharge database to estimate prevalence and incidence. P. Trerotoli, N. Bartolomeo, A.M. Moretti, G. Serio.

Background and aim. Chronic Obstructive Pulmonary Disease (COPD), although largely preventable, is a great health burden in all the countries worldwide. Statistics of morbidity and mortality of COPD show the need for correct management of the disease. Chronic Obstructive Respiratory Diseases (DRG 88) are in 9th place for discharge in in-patient hospital admission. It is necessary to establish specific indicators which are efficacious and relevant for the patient, the doctor and the health manager. This study will analyse the information in respect of hospital admissions (Hospital discharge database) in Puglia for the period 2000-2005.

Methods. The analysis was carried out utilising the Puglia Region hospital patient discharge database, selecting those patients with admission for chronic respiratory disease as principal or secondary diagnosis.

Results. Chronic respiratory diseases are more frequent in males and in people over 45 years old with frequency increasing with age. Geographical distribution shows that there are greater rates of hospitalisation in big cities and in the neighbourhood of industrial areas. Although the trend over time is slight. A higher percentage of re-admission has been found for patients with COPD, and the interval between the two admissions occurs within one or two months; the diagnosis at the second admission is the same as for the first. $10.6 \%$ of discharge forms report one diagnosis, especially in patients older than 65 years of age. Little could be said about diagnostic procedures because these are not reported on the discharge form.

Conclusion. Hospitalisation data confirms expectations regarding age and sex of patients. The high hospitalisation rates indicate that in-patients care still remains the only viable treatment for COPD and other chronic respiratory diseases. The high number of exacerbations reflect the absence of out-patients service or community care, and the same diagnosis in more than one episode shows the lack of efficiency of health services and disease management. This data is necessary to understand disease distribution and the modification of disease management in order to reduce health care costs, to increase efficacy in disease control and to limit repeated exacerbation and so to obtain the maximum benefit for the patients. Monaldi Arch Chest Dis 2008; 69: 3, 94-106.

Keywords: COPD, Administrative database, Re-admission, Comorbidity.

1 Department of Biomedical Science and Human Oncology, Department of medical statistics University of Bari;

2 Pneumology Unit, Bari University Public Hospital, Bari, Italy.

Correspondence: Trerotoli Paolo, Department of Biomedical Science and Human Oncology, Section of Medical Statistic, University of Bari, P.za G. Cesare 1, 70124 Bari, Italy; e-mail: trerotoli@igiene.uniba.it

\section{Introduction}

Chronic Obstructive Pulmonary Disease (COPD), although largely preventable, is a great health burden in all countries worldwide. Looking into the future there is no indication that there will be a reduction in smoking or in atmospheric pollution. Statistics of morbidity and mortality of COPD show the need for correct management of the disease.

In the United States, from 1999 to 2004 COPD was the fourth cause of death, after cardiovascular disease, malignant tumours and cerebrovascular disease, accounting for approximately $5 \%$ of total deaths in both 2003 and 2004 [1]. In Italy in 2004, respiratory diseases were the third cause of death, after circulatory system diseases and tumours [2], with $50 \%$ of these attributable to COPD.
According to the forecasts of Murray and Lopez [3], there will be a large increase in worldwide COPD morbidity over the next years with it moving from $12^{\text {th }}$ to $5^{\text {th }}$ position in the scale of prevalence by 2020 . It is now commonly held that the diagnosis of COPD is seriously underestimated with respect to the real occurrence of the disease, both because of medical discernment and a low level of awareness among patients. The rate of prevalence of recorded COPD in Italy is similar to that of other industrialised countries. From data supplied by ISTAT (Italian Statistical Institute) [4], chronic obstructive respiratory diseases are more common among males $(4.8 \%$ ) than among females (4.2\%). Chronic bronchitis and emphysema are in $4^{\text {th }}$ place for prevalence if we consider those older individuals: in the age range from 65-69 the prevalence is $11.8 \%$ for males and $8.6 \%$ for females, in 
the range $70-74$ it is $14.8 \%$ and $9.7 \%$ respectively, in the range $75-79$ it is $22.4 \%$ and $12.1 \%$ respectively and for 80 -year-olds and over it is $25.3 \%$ for males and $15.8 \%$ for females. The enormous health burden which is imposed by COPD can be found in the latest data available from 2003 [5]. This shows that DRG 88 (DRG: Diagnosis Related Group) i.e. Chronic Obstructive Respiratory Diseases, stands in $9^{\text {th }}$ place in respect of those patients discharged after in-patient hospital admission with a total of 113,959 discharges $(1,4 \%$ of total) and 997,724 bed-occupancy days for an average of 8.8 days.

The absence of symptoms in the early stages of COPD together with its slow progression and late appearance of disability can partly explain the absence of an active campaign of preventions but much could be done in terms of a diagnosis both nosologically sustainable and made earlier than usual, with the recognition of symptoms which are unfortunately often misinterpreted.

Today COPD as a cause of death is increasing, we can no longer put off a worldwide commitment to its early diagnosis.

It is necessary to establish specific indicators which are efficacious and relevant for the patient, the doctor and the health manager. Recent studies have confirmed that the most reliable indicator is the classification of the "acute exacerbation number": for the patient because the frequency of exacerbations greatly affects the quality of life; for the doctor because it greatly affects the type of treatment required with regard to hospitalisation and drug consumption; and for the manager because acute exacerbation greatly affects direct costs, drugs and hospitalisation, and also indirect costs [6-11].

The need to optimise resources and improve the quality of life of patients has led to an increase in home treatment even for situations which are complex and need technological applications and these include treatment for patients with chronic respiratory insufficiency, but as of now the lack of scientific evidence for its clinical and financial efficiency has not allowed its development especially in terms of costs and payments [12-15].

International evidence-based guidelines are necessary but are not sufficient for the correct management of this disease $[16,17]$.

It is a priority for the health service to tackle the problem of COPD [18], well identified by Italian National Health Service, that has considered specific action in the National Health Plan 20062008 [19] even though the outcome of proposed action is not yet known.

Knowledge of epidemiological data for COPD is essential for the definition of the best strategies to adopt and studies on prevalence must be included in these. Currently there are studies being carried out among general practitioners to evaluate patient compliance to treatment and for the gravity of COPD as defined by the GOLD (Global Initiative for Chronic Obstructive Lung Disease) guidelines. Other useful information can be gleaned from the databases for hospital admissions and deaths.
This study will analyse the information relative to hospital admission (Hospital discharge database) in the Italian Region of Puglia for the period 2000-2005. The information in this database is especially reliable because of the quality of its compilation and the fact that the information therein contained has already been used to modify various aspects of the regional health system including the hospital reorganisation plan, the definition and application of essential care levels and the evaluation of appropriateness of admission.

\section{Methods}

The analysis was carried out using the Puglia Region hospital patient discharge database, selecting those discharges for chronic respiratory disease in the period 2000-2005 as principal or secondary diagnosis with following ICD-9-CM codes:

491.0 - Simple chronic bronchitis;

491.1 - Mucopurulent chronic bronchitis;

491.20 - Obstructive chronic bronchitis without mention of acute exacerbation;

491.21 - Obstructive chronic bronchitis with acute exacerbation;

491.8 - Other chronic bronchitis;

491.9 - Unspecified chronic bronchitis;

492 - Emphysema;

493 - Asthma;

518.81 - Respiratory failure.

In 2000 diagnosis ICD-9 was still in use and COPD was indicated as 491.2 and not until 2001 was it separated into 491.20 without acute exacerbation, and 491.21 with acute exacerbation. For those patients classified as 491.2 we have assigned the code 491.20.

For the creation of the hospitalisation map we have used rates adjusted for sex and age ranges. The adjustment was carried out using a direct standardisation, with the reference population that of Puglia for the entire period under consideration. For the analysis of re-admission we accept re-admission only if it is under the same regime as the previous admission. $\chi$-square and Cochran-Armitage test for trend have been performed to evaluate difference and trends in percentage.

Analyses have been performed using software SAS 9.1 for personal computer.

\section{Results}

The number of discharge records which matched the criteria were 350,176 for discharge as in-patient (IP) and 17,499 as day hospital patients (DH) (table 1). Frequency of admission for males as in-patient was $67.4 \%$ and as day-hospital $65.6 \%$ giving ratios $\mathrm{M} / \mathrm{F}$ of 2.0 for IP and 1.9 for $\mathrm{DH}$. From table 1 we can see that males are always in the majority, it becoming more evident as age increases $\left(\chi^{2}=3567, p<0.0001\right.$; test for trend: $p<0.0001)$. Over $70 \%$ of admissions for chronic respiratory disease are for people over 45 years of age with $73.9 \%$ for $\mathrm{DH}$ and for $93.6 \%$ IP.

Limiting the analysis to patients with chronic respiratory disease as the principal diagnosis (table 2) IP 


\begin{tabular}{|c|c|c|c|c|c|c|c|c|c|c|}
\hline \multirow{4}{*}{ Age Range } & \multicolumn{5}{|c|}{ In-Patients } & \multicolumn{5}{|c|}{ Day-hospital } \\
\hline & \multicolumn{4}{|c|}{ Sex } & \multirow{3}{*}{ Totals } & \multicolumn{4}{|c|}{ Sex } & \multirow{3}{*}{ Totals } \\
\hline & \multicolumn{2}{|c|}{ Female } & \multicolumn{2}{|c|}{ Male } & & \multicolumn{2}{|c|}{ Female } & \multicolumn{2}{|c|}{ Male } & \\
\hline & $\mathbf{N}^{\circ}$ & $\%$ & $\mathbf{N}^{\circ}$ & $\%$ & & $\mathbf{N}^{\circ}$ & $\%$ & $\mathbf{N}^{\circ}$ & $\%$ & \\
\hline < 1 year old & 1075 & $0.9 \%$ & 1834 & $0.8 \%$ & 2909 & 28 & $0.5 \%$ & 43 & $0.4 \%$ & 71 \\
\hline $1-4$ & 1643 & $1.4 \%$ & 2557 & $1.1 \%$ & 4200 & 222 & $3.7 \%$ & 317 & $2.8 \%$ & 539 \\
\hline $5-14$ & 1160 & $1.0 \%$ & 2009 & $0.9 \%$ & 3169 & 466 & $7.8 \%$ & 828 & $7.2 \%$ & 1294 \\
\hline $15-24$ & 966 & $0.8 \%$ & 1079 & $0.5 \%$ & 2045 & 261 & $4.3 \%$ & 375 & $3.3 \%$ & 636 \\
\hline $25-44$ & 3861 & $3.4 \%$ & 5915 & $2.5 \%$ & 9776 & 974 & $16.2 \%$ & 1042 & $9.1 \%$ & 2016 \\
\hline $45-64$ & 16914 & $14.8 \%$ & 42708 & $18.1 \%$ & 59622 & 1869 & $31.1 \%$ & 3652 & $31.8 \%$ & 5521 \\
\hline $65-74$ & 29322 & $25.7 \%$ & 77340 & $32.8 \%$ & 106662 & 1254 & $20.9 \%$ & 3080 & $26.8 \%$ & 4334 \\
\hline$>75$ & 59186 & $51.9 \%$ & 102607 & $43.5 \%$ & 161793 & 937 & $15.6 \%$ & 2151 & $18.7 \%$ & 3088 \\
\hline Totals & 114127 & $100.0 \%$ & 236049 & $100.0 \%$ & 350176 & 6011 & $100.0 \%$ & 11488 & $100.0 \%$ & 17499 \\
\hline
\end{tabular}

Table 2. - Distribution for in-patient and day hospital, sex and age range for admission with a diagnosis of chronic respiratory disease in the principal diagnosis field of the discharge record

\begin{tabular}{|c|c|c|c|c|c|c|c|c|c|c|}
\hline \multirow{4}{*}{ Age Range } & \multicolumn{5}{|c|}{ In-Patients } & \multicolumn{5}{|c|}{ Day-hospital } \\
\hline & \multicolumn{4}{|c|}{ Sex } & \multirow{3}{*}{ Totals } & \multicolumn{4}{|c|}{ Sex } & \multirow{3}{*}{ Totals } \\
\hline & \multicolumn{2}{|c|}{ Female } & \multicolumn{2}{|c|}{ Male } & & \multicolumn{2}{|c|}{ Female } & \multicolumn{2}{|c|}{ Male } & \\
\hline & $\mathbf{N}^{\circ}$ & $\%$ & $\mathbf{N}^{\circ}$ & $\%$ & & $\mathbf{N}^{\circ}$ & $\%$ & $\mathbf{N}^{\circ}$ & $\%$ & \\
\hline$<1$ year old & 877 & $2.0 \%$ & 1494 & $1.6 \%$ & 2371 & 22 & $0.6 \%$ & 32 & $0.6 \%$ & 54 \\
\hline $1-4$ & 1289 & $2.9 \%$ & 2028 & $2.2 \%$ & 3317 & 191 & $5.4 \%$ & 274 & $5.0 \%$ & 465 \\
\hline $5-14$ & 837 & $1.9 \%$ & 1470 & $1.6 \%$ & 2307 & 413 & $11.7 \%$ & 744 & $13.7 \%$ & 1157 \\
\hline $15-24$ & 639 & $1.4 \%$ & 680 & $0.8 \%$ & 1319 & 235 & $6.6 \%$ & 342 & $6.3 \%$ & 577 \\
\hline $25-44$ & 2171 & $4.9 \%$ & 2898 & $3.2 \%$ & 5069 & 810 & $22.9 \%$ & 775 & $14.3 \%$ & 1585 \\
\hline $45-64$ & 7594 & $17.1 \%$ & 16219 & $17.9 \%$ & 23813 & 1074 & $30.3 \%$ & 1626 & $29.9 \%$ & 2700 \\
\hline $65-74$ & 11287 & $25.4 \%$ & 29169 & $32.2 \%$ & 40456 & 512 & $14.4 \%$ & 1045 & $19.2 \%$ & 1557 \\
\hline$>75$ & 19792 & $44.5 \%$ & 36590 & $40.4 \%$ & 56382 & 287 & $8.1 \%$ & 598 & $11.0 \%$ & 885 \\
\hline Totals & 44486 & $100.0 \%$ & 90548 & $100.0 \%$ & 135034 & 3544 & $100.0 \%$ & 5436 & $100.0 \%$ & 8980 \\
\hline
\end{tabular}

were 135,034 and $\mathrm{DH} 8,980$. The $\mathrm{M} / \mathrm{F}$ ratios were 2.0 for IP, $67.1 \%$ male, and 1.5 for $\mathrm{DH}$, males $60.5 \%$. Also in table 2 we can see that patients over 45-year-old are more frequent, a trend rising with age $\left(\chi^{2}=1114, \mathrm{p}<0.0001\right.$; test for trend: $p<0.0001)$. In the case of $\mathrm{DH}$ we can see an increase in admission in the age range of 25-44 and $45-64$, followed by a decrease in over 65 's.

Figure 1 shows for the Puglia Region the geographic distribution of admission (IP + $\mathrm{DH})$ with a principal diagnosis of chronic respiratory disease. The rates are between 11.4/ 1000 and 140.6/1000 inhabitants. The areas with the highest rates are Salento, the Pro-

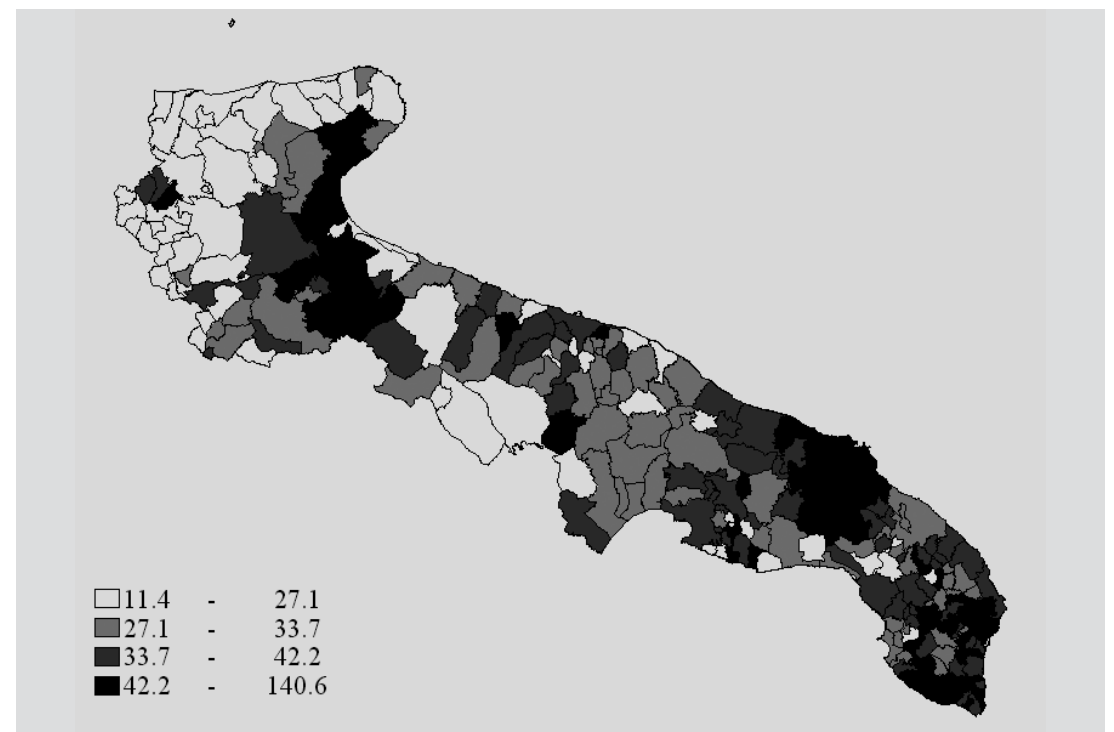

Fig. 1. - Hospitalisation rate adjusted for gender and age range with principal diagnosis of chronic respiratory disease. 
Table 3. - Distribution for sex and principal diagnosis of patients discharged in the period 2000-2005 both as in-patients and day-hospital

\begin{tabular}{|c|c|c|c|c|c|}
\hline \multirow{3}{*}{ Diagnosis } & \multicolumn{4}{|c|}{ Sex } & \multirow{3}{*}{ Totals } \\
\hline & \multicolumn{2}{|c|}{ Female } & \multicolumn{2}{|c|}{ Male } & \\
\hline & $\mathbf{N}^{\circ}$ & $\%$ & $\mathbf{N}^{\circ}$ & $\%$ & \\
\hline 491.0 - Simple chronic bronchitis & 745 & $2.2 \%$ & 1050 & $1.9 \%$ & 1795 \\
\hline 491.1 - Mucopurulent chronic bronchitis & 784 & $2.3 \%$ & 1376 & $2.5 \%$ & 2160 \\
\hline 491.20 - Obstructive chronic bronchitis without mention of acute exacerbation & 6099 & $17.7 \%$ & 12518 & $22.7 \%$ & 18617 \\
\hline 491.21 - Obstructive chronic bronchitis with acute exacerbation & 10458 & $30.3 \%$ & 18053 & $32.7 \%$ & 28511 \\
\hline 491.8 - Other chronic bronchitis & 469 & $1.4 \%$ & 674 & $1.2 \%$ & 1143 \\
\hline 491.9 - Unspecified chronic bronchitis & 831 & $2.4 \%$ & 963 & $1.7 \%$ & 1794 \\
\hline $492 \quad$ - Emphysema & 105 & $0.3 \%$ & 545 & $1.0 \%$ & 650 \\
\hline 493 - Asthma & 7227 & $20.9 \%$ & 7736 & $14.0 \%$ & 14963 \\
\hline 518.81 - Respiratory failure & 7781 & $22.6 \%$ & 12307 & $22.3 \%$ & 20088 \\
\hline Totals & 34499 & $100.0 \%$ & 55222 & $100.0 \%$ & 89721 \\
\hline
\end{tabular}

vincial capital cities and surrounding areas as the southern part of Foggia, and the areas of high industrialisation as in the Provinces of Brindisi, Taranto and town near the gulf of Manfredonia.

Table 3 shows the frequency of the principal diagnoses found on the Discharge Records of the patients hospitalised with chronic respiratory disease. COPD with and without acute exacerbation (code ICD9-CM 491.20 e 491.21), respiratory failure (code ICD9-CM 518.81) and asthma (code ICD9CM 493) are those most frequently found. The common cause of inpatient admission is acute exacerbation of COPD $(31.8 \% ; 28,544 /$ $89,721)$, followed by respiratory failure $(22.4 \% ; 20,088 / 89,721)$ and COPD without acute exacerbation $(20,7 \% ; 18,617 / 89,721)$. This third most common cause is also the second cause $(29.4 \% ; 2,442 / 8,308)$ for day-hospitalisation after asthma $(41.8 \% ; 3,473 / 8,308)$.

The age distribution shows that the principal diagnosis of COPD with or without acute exacerbation and/or respiratory failure are more frequent in the higher age groups (figure 2). In-patient admissions for COPD without acute exacerbation are 16,175 with $77.8 \%$ in the age groups 65-74 and over 75; dayhospital are 2,442 with only $49.9 \%$ in the same age groups. In-patients diagnosed with COPD with acute exacerbation were 27,345 , principally in the older age groups with a rising trend as age increases: $17.1 \%$ for the age group $45-64,29.5 \%$ in group $65-74$ and $50.8 \%$ for the
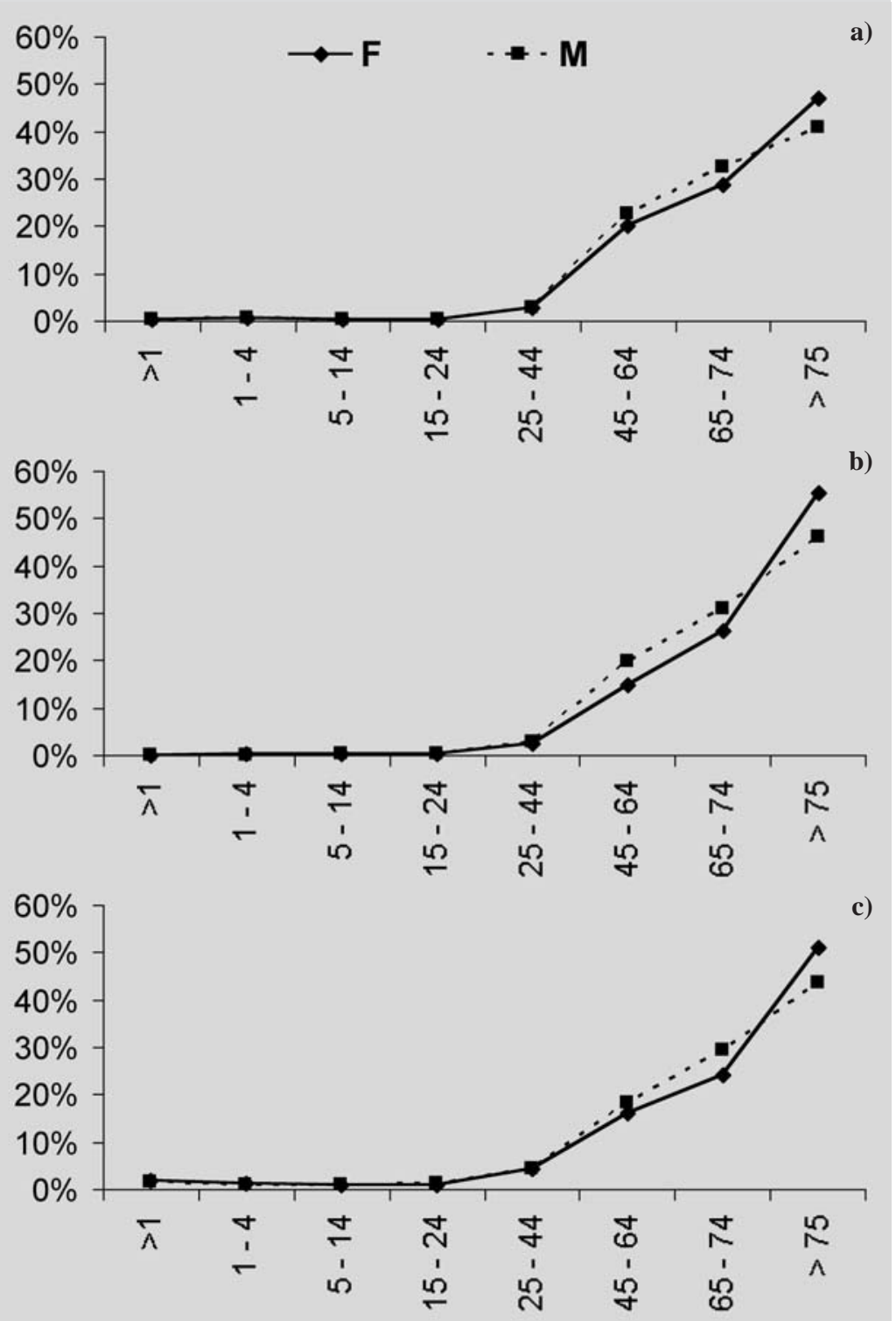

Fig. 2. - Distribution for sex and age range for in-patients and day-hospital with a principal diagnosis of COPD without acute exacerbation (fig. 2a), COPD with acute exacerbation (fig. $2 b)$ and respiratory failure (fig. $2 \mathrm{c}$ ). 
over 75 's. Of the 1,166 day-hospital there were $38.2 \%$ in the age group $45-64,24.4 \%$ in group $65-74$ and $17.7 \%$ for the over 75 's.

In-patients diagnosed with respiratory failure were 19,892 with almost half of them over 75 years of age. More precisely there were $17.4 \%$ in the age group 45-64, 27.3\% in group 65-74 and $46.5 \%$ over 75 . Day-hospital with the same diagnosis were relatively evenly divided among the age groups with $26 \%$ in the group $45-64,30.6 \%$ in group 65-74 and $28.1 \%$ over 75 .

Admissions for chronic respiratory disease showed that asthma is more frequent in a young age for both in-patients and day-hospital (IP: age group $1-423.1 \%$, group 5-14 $15.8 \%$, group $15-247.1 \%$, group 25-44 15.8\%; DH: age group 1-4 10.2\%, group 5-14 $27.2 \%$, group $15-2413,2 \%$, group $25-$ $4429.2 \%$ ).

There is a substantial difference between the sexes in the age distribution for admissions. For males admission frequency already begins to rise from the age group 45-64 while for females there is a peak only in the over 75 's with a higher increase than that for males. This difference in age distribution is evident in all three principal diagnoses examined $\left(\chi^{2}=455\right.$; $p<0.0001$; test for trend: $p<0.0001)$.

The total number of admissions, both in-patient and out-patient, for COPD with and without acute exacerbation increased from 15,913 in 2000 to 22.530 in 2005 with the largest yearly increase $(19 \%)$ between 2000 and 2001 to 18.969 and a $10 \%$ increase from 2004 to 2005 (from 20,379 a 22,530) (figure 3). From 2001 with the new codes 491.20 without acute exacerbation, and 491.21 with acute exacerbation, it can be seen that the diagnosis with acute exacerbation is responsible for the majority of admissions. It can also be seen that admissions for COPD without acute exacerbation reduced between 2001 and 2002, becoming stable in the following years. Conversely admissions for COPD with acute exacerbation shows a small but constant rise from 2001 to 2005. More evident is the increasing trend for admission, for both IP and $\mathrm{DH}$, with the diagnosis of respiratory failure.

The standardised rate shows, both in the case of COPD with and without acute exacerbation and of respiratory failure, a more evident rise for men than for women in hospitalisation (figure 4). In particular, the hospitalisation rate for

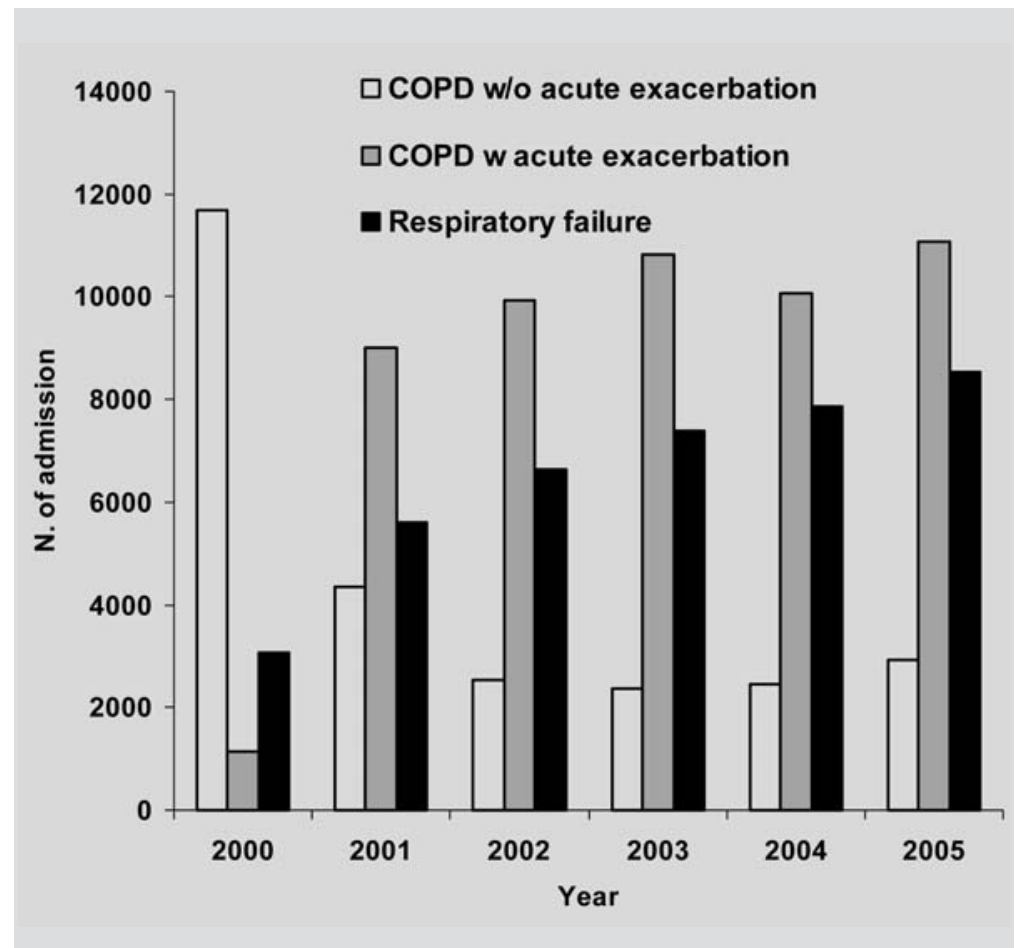

Fig. 3. - Distribution for admission year with diagnosis of COPD without acute exacerbation (491.20), COPD with acute exacerbation (491.21) and respiratory failure (518.81).

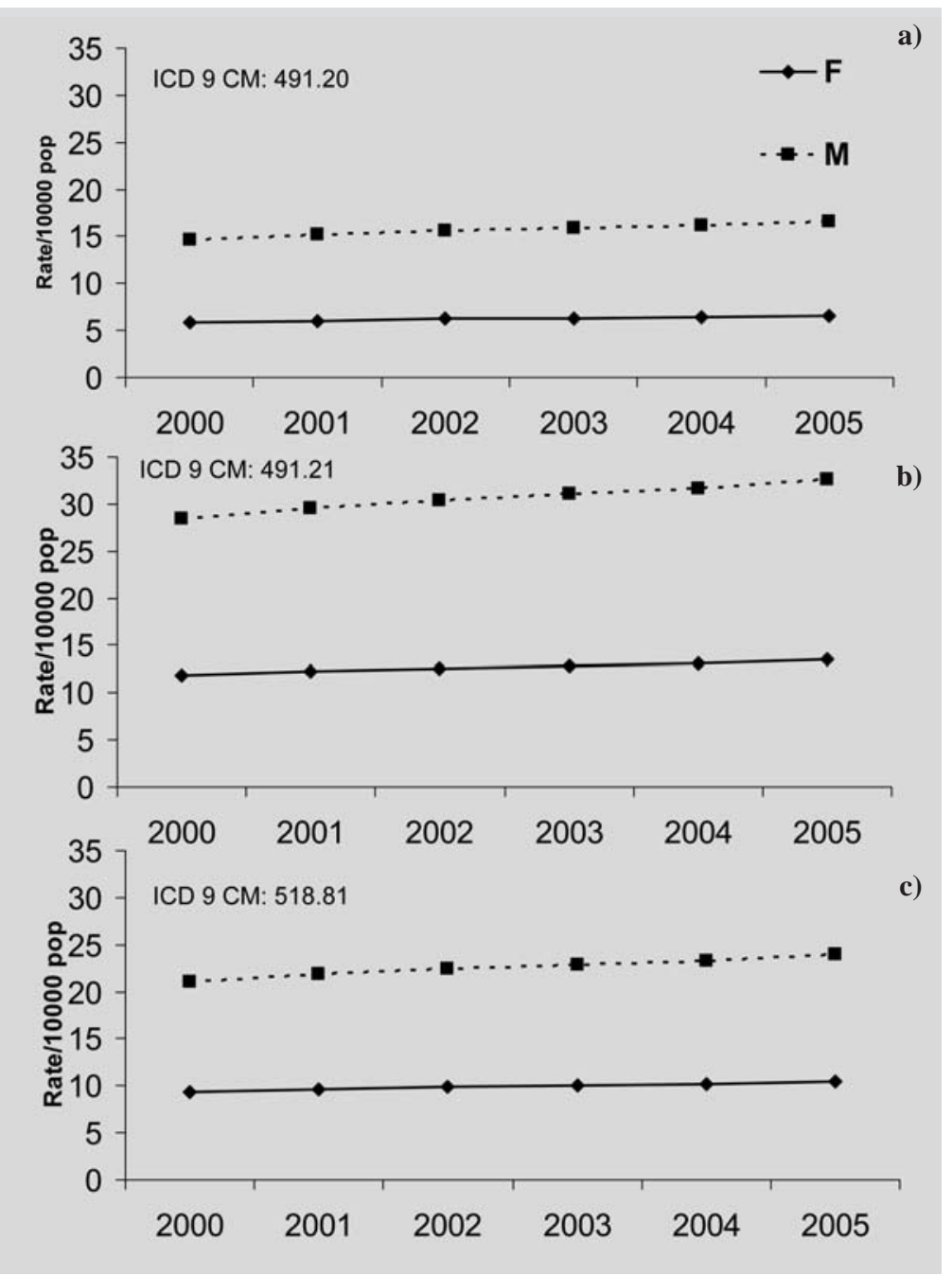

Fig. 4. - Standardised hospitalisation rate over time for COPD without acute exacerbation (fig. 4a), COPD with acute exacerbation (fig. 4b) and respiratory failure (fig. 4c). 
COPD without acute exacerbation increases from $14.6 / 10,000$ in 2000 to $16.6 / 10,000$ in 2005 in males, while for females the increase is from $5.9 / 10,000$ to $6.6 / 10,000$ for the same period (figure 4a).

The rate is higher for COPD with acute exacerbation for both males and females in the same period. For males the rate progressively changes from 28.4 to 32.6 per 10,000 while for females it goes from 11.9 to 13.5 per 10,000 (figure $4 \mathrm{~b}$ ).

Hospitalisation for respiratory failure also shows a rising trend both in males and females with a larger rise for males. From 2000 to 2005 there is an increase from 21.1 per 10,000 to 23.9/10,000 while for females the rate increases less from 9.4 to 10.5 per 10,000 (figure $4 \mathrm{c}$ ). The rise in respiratory failure is less than that of COPD with acute exacerbation.
Most of the discharged patients had only one hospital admission (table 4) but chronic respiratory problems caused more than one admission for many patients with a multiple admission rate varying from $13.1 \%$ to $32.8 \%$ in the period $2000-2005$. For in-patients with respiratory failure, $13.6 \%$ have two hospital admissions, $5.5 \%$ have three, $2.8 \%$ have four and $5.0 \%$ have five or more with a total of $26.9 \%$ of patients with re-admissions. For in-patients with COPD with acute exacerbation the two-admission rate is slightly higher (15.2\%) while for those without acute exacerbation the rate is at $14.1 \%$. Comparing COPD with and without acute exacerbation the rates are for three admissions $5.5 \%$ compared to $6.1 \%$ while for those patients with 5 admissions or more the rate is $4.0 \%$ instead of $9.0 \%$ (test for trend: $p<0.0001$ ). The

Table 4. - Frequency of the episodes of repeated admission in 2000-2005 in relation to the principal diagnosis at first admission. The upper table refers to in-patients; the lower table refers to day-hospital. The percentages are referred to the number of patients in each diagnosis

\begin{tabular}{|c|c|c|c|c|c|c|c|c|c|c|c|c|}
\hline \multirow{2}{*}{ Diagnosis - Inpatients } & \multirow{2}{*}{$\begin{array}{c}\text { Total } N^{\circ} \\
\text { DR }\end{array}$} & \multirow{2}{*}{$\begin{array}{c}\mathbf{N}^{\circ} \\
\text { Patients } \\
(*)\end{array}$} & \multicolumn{2}{|c|}{$\begin{array}{l}\text { Patients with } \\
1 \text { admission }\end{array}$} & \multicolumn{2}{|c|}{$\begin{array}{l}\text { Patients with } \\
2 \text { admissions }\end{array}$} & \multicolumn{2}{|c|}{$\begin{array}{l}\text { Patients with } \\
3 \text { admissions }\end{array}$} & \multicolumn{2}{|c|}{$\begin{array}{l}\text { Patients with } \\
4 \text { admissions }\end{array}$} & \multicolumn{2}{|c|}{$\begin{array}{l}\text { Patients with } \\
5 \text { admissions }\end{array}$} \\
\hline & & & $\mathbf{n}^{\circ}$ & $\%$ & $n^{\circ}$ & $\%$ & $\mathbf{n}^{\circ}$ & $\%$ & $\mathrm{n}^{0}$ & $\%$ & $\mathbf{n}^{\circ}$ & $\%$ \\
\hline 491.0 - Simple chronic bronchitis & 1821 & 1234 & 987 & $80.0 \%$ & 136 & $11.0 \%$ & 52 & $4.2 \%$ & 24 & $1.9 \%$ & 35 & $2.8 \%$ \\
\hline 491.1 - Mucopurulent chronic bronchitis & 3638 & 2076 & 1556 & $75.0 \%$ & 251 & $12.1 \%$ & 86 & $4.1 \%$ & 52 & $2.5 \%$ & 131 & $6.3 \%$ \\
\hline $\begin{array}{l}491.20 \text { - Obstructive chronic bronchitis } \\
\text { without mention of acute exacerbation }\end{array}$ & 33237 & 16175 & 10864 & $67.2 \%$ & 2284 & $14.1 \%$ & 989 & $6.1 \%$ & 577 & $3.6 \%$ & 1461 & $9.0 \%$ \\
\hline $\begin{array}{l}491.21 \text { - Obstructive chronic bronchitis } \\
\text { with acute exacerbation }\end{array}$ & 43703 & 27345 & 19925 & $72.9 \%$ & 4149 & $15.2 \%$ & 1507 & $5.5 \%$ & 672 & $2.5 \%$ & 1092 & $4.0 \%$ \\
\hline 491.8 - Other chronic bronchitis & 1835 & 958 & 654 & $68.3 \%$ & 131 & $13.7 \%$ & 52 & $5.4 \%$ & 44 & $4.6 \%$ & 77 & $8.0 \%$ \\
\hline 491.9 - Unspecified chronic bronchitis & 2310 & 1684 & 1376 & $81.7 \%$ & 183 & $10.9 \%$ & 60 & $3.6 \%$ & 27 & $1.6 \%$ & 38 & $2.3 \%$ \\
\hline 492 - Emphysema & 1028 & 559 & 400 & $71.6 \%$ & 75 & $13.4 \%$ & 27 & $4.8 \%$ & 23 & $4.1 \%$ & 34 & $6.1 \%$ \\
\hline 493 - Asthma & 14228 & 11490 & 9984 & $86.9 \%$ & 991 & $8.6 \%$ & 271 & $2.4 \%$ & 103 & $0.9 \%$ & 141 & $1.2 \%$ \\
\hline 518.81 - Respiratory failure & 33234 & 19892 & 14527 & $73.0 \%$ & 2715 & $13.6 \%$ & 1101 & $5.5 \%$ & 553 & $2.8 \%$ & 996 & $5.0 \%$ \\
\hline Totals & 135034 & 81413 & 60273 & $74.0 \%$ & 10915 & $13.4 \%$ & 4145 & $5.1 \%$ & 2075 & $2.5 \%$ & 4005 & $4.9 \%$ \\
\hline \multirow{2}{*}{ Diagnosis - Day-Hospital } & \multirow{2}{*}{$\begin{array}{c}\text { Total } N^{\circ} \\
\text { DR }\end{array}$} & \multirow{2}{*}{$\begin{array}{c}\mathbf{N}^{\circ} \\
\text { Patients } \\
(*)\end{array}$} & \multicolumn{2}{|c|}{$\begin{array}{l}\text { Patients with } \\
1 \text { admission }\end{array}$} & \multicolumn{2}{|c|}{$\begin{array}{l}\text { Patients with } \\
2 \text { admissions }\end{array}$} & \multicolumn{2}{|c|}{$\begin{array}{l}\text { Patients with } \\
3 \text { admissions }\end{array}$} & \multicolumn{2}{|c|}{$\begin{array}{l}\text { Patients with } \\
4 \text { admissions }\end{array}$} & \multicolumn{2}{|c|}{$\begin{array}{l}\text { Patients with } \\
5 \text { admissions }\end{array}$} \\
\hline & & & $\mathbf{n}^{\circ}$ & $\%$ & $n^{\circ}$ & $\%$ & $\mathbf{n}^{\circ}$ & $\%$ & $\mathbf{n}^{\circ}$ & $\%$ & $n^{\circ}$ & $\%$ \\
\hline 491.0 - Simple chronic bronchitis & 589 & 561 & 536 & $95.5 \%$ & 22 & $3.9 \%$ & 3 & $0.5 \%$ & - & - & - & - \\
\hline 491.1 - Mucopurulent chronic bronchitis & 90 & 84 & 78 & $92.9 \%$ & 6 & $7.1 \%$ & - & - & - & - & - & - \\
\hline $\begin{array}{l}491.20 \text { - Obstructive chronic bronchitis } \\
\text { without mention of acute exacerbation }\end{array}$ & 2673 & 2442 & 2252 & $92.2 \%$ & 160 & $6.6 \%$ & 22 & $0.9 \%$ & 6 & $0.2 \%$ & 2 & $0.1 \%$ \\
\hline $\begin{array}{l}491.21 \text { - Obstructive chronic bronchitis } \\
\text { with acute exacerbation }\end{array}$ & 1307 & 1166 & 1060 & $90.9 \%$ & 80 & $6.9 \%$ & 22 & $1.9 \%$ & 3 & $0.3 \%$ & 1 & $0.1 \%$ \\
\hline 491.8 - Other chronic bronchitis & 202 & 185 & 171 & $92.4 \%$ & 12 & $6.5 \%$ & 1 & $0.5 \%$ & 1 & $0.5 \%$ & - & - \\
\hline 491.9 - Unspecified chronic bronchitis & 120 & 110 & 101 & $91.8 \%$ & 8 & $7.3 \%$ & 1 & $0.9 \%$ & - & - & - & - \\
\hline 492 - Emphysema & 102 & 91 & 80 & $87.9 \%$ & 11 & $12.1 \%$ & - & - & - & - & - & - \\
\hline 493 - Asthma & 3679 & 3473 & 3297 & $94.9 \%$ & 152 & $4.4 \%$ & 20 & $0.6 \%$ & 3 & $0.1 \%$ & 1 & $0.0 \%$ \\
\hline 518.81 - Respiratory failure & 218 & 196 & 179 & $91.3 \%$ & 12 & $6.1 \%$ & 5 & $2.6 \%$ & - & - & - & - \\
\hline Totals & 8980 & 8308 & 7754 & $93.3 \%$ & 463 & $5.6 \%$ & 74 & $0.9 \%$ & 13 & $0.2 \%$ & 4 & $0.0 \%$ \\
\hline
\end{tabular}

E.g. First line $80.0 \%=(987 / 1234) * 100 ; 11.0 \%=(136 / 1234) * 100$.

(*) The patients have been classified in reference to the diagnosis at first admission. 
multiple admission rate for patients with COPD with acute exacerbation is $27.2 \%$ and for COPD without acute exacerbation it is $32.8 \%$.

A deeper analysis shows that in most cases the diagnosis in admission and in readmission is the same (figure 5). A principal diagnosis of COPD without acute exacerbation at first admission is repeated in $56 \%$ of cases of re-admission and in more than half of these $(25.3 \%$ of total re-admission cases) the readmission is in the period from 2 to 6 months. Readmission with a diagnosis of COPD with acute exacerbation is $23.3 \%$ (figure 5a) with $10.6 \%$ in the period from 7 to 12 months. Only in $10.7 \%$ of patients with a diagnosis of COPD without complications was there a diagnosis of respiratory failure in the second admission with $3.1 \%$ of second admission within a month.

A principal diagnosis of COPD with acute exacerbation at first admission is repeated in $66.3 \%$ of cases of re-admission (figure 5b). In particular in $27.1 \%$ of total cases the re-admission is in the
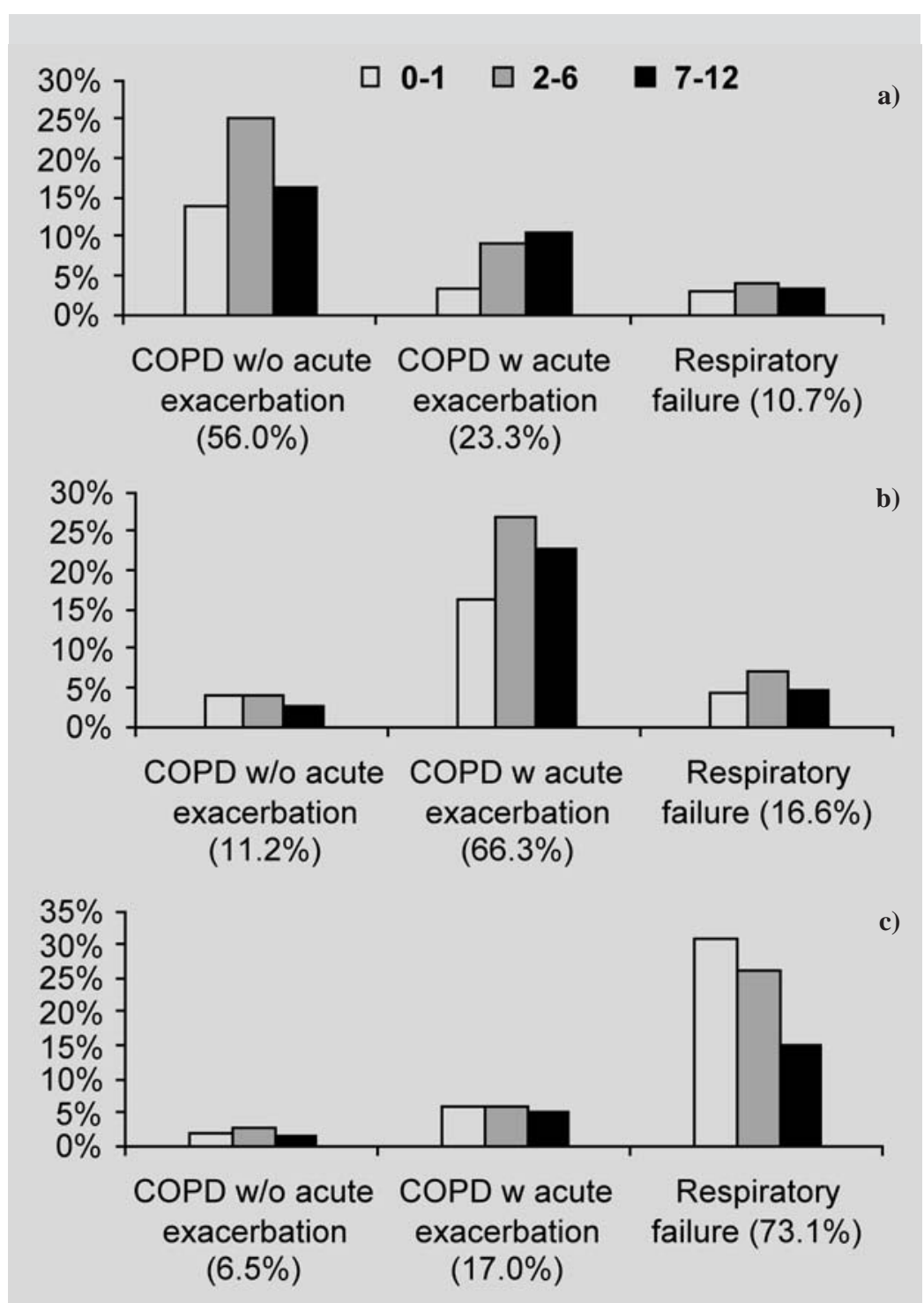

Fig. 5. - Distribution of repeated admissions for the principal diagnosis of the second admission and the months between the two successive events for the admissions on the first occasion with principal diagnosis of a) COPD without acute exacerbation; b) COPD with acute exacerbation; c) respiratory failure. period from 2 to 6 months and $22.8 \%$ in the $7-12$ month period. Instead $16.6 \%$ of patients are readmitted with a diagnosis of respiratory failure with $7.2 \%$ of cases within 2-6 months.

For those patients with a first admission with a diagnosis of respiratory failure in $73.1 \%$ of the cases the same diagnosis was made at the second admission with $31.3 \%$ of cases re-admitted within the first month. $17 \%$ of cases had a diagnosis at readmission of COPD with acute exacerbation.

The quantity and types of secondary diagnoses presented on the discharge records help define the complexity of patients with obstructive bronchopneumopathy. Only $10.6 \%$ of the in-patient records show only a principal diagnosis (table 5) while $23 \%$ show one secondary diagnosis and $28 \%$ show two of them. It must be highlighted that some principal diagnoses are more easily associated with a larger number of secondary diagnoses: respiratory failure and non-specific chronic bronchitis, for example, are frequently linked to three secondary diagnoses $30.6 \%$ and $34.5 \%$ respectively. Of the records with a principal diagnosis of COPD with and without acute exacerbation respectively $29.8 \%$ and $29.6 \%$ show a secondary diagnosis.

Day-hospital records with only the principal diagnosis are the most common, there being $48.7 \%$ of them, and $31.4 \%$ show only one secondary diagnosis. However a principal diagnosis of respiratory failure, even in day-hospital, has $32.1 \%$ of records with three more diagnoses.

Examining in more detail COPD with and without acute exacerbation it can be seen that in the over 65's there is a higher percentage of records with three or more secondary diagnoses. Figure $6 \mathrm{a}$ shows this markedly for females with a diagnosis of COPD without acute exacerbation. In the cases of admission for COPD with acute exacerbation the majority of records have no or only one secondary diagnosis (figure $6 \mathrm{~b}$ ).

Tables 6 and 7 show the comorbidities more frequently associated with chronic respiratory disease. COPD with and without acute exacerbation is most frequently associated with the principal diagnosis of respiratory failure $(18.8 \%)$ but also with other chronic pulmonary diseases. In a small number of cases, the same diagnosis is indicated as principal and secondary diagnosis (1.7\% COPD without acute exacerbation and $2.6 \%$ COPD with acute exacerbation). This is certainly an error in the compilation of the record. Car- 
Table 5. - Distribution of the discharge records for principal diagnosis and number of secondary diagnoses reported on discharge record. Puglia 2000-2005

\begin{tabular}{|c|c|c|c|c|c|c|c|c|c|c|c|}
\hline \multirow{3}{*}{ Principal diagnosis In-patients } & \multicolumn{11}{|c|}{ Number of secondary diagnoses } \\
\hline & \multicolumn{2}{|c|}{0} & \multicolumn{2}{|c|}{1} & \multicolumn{2}{|c|}{2} & \multicolumn{2}{|c|}{3} & \multicolumn{2}{|c|}{4 or more } & \multirow{2}{*}{ Tota } \\
\hline & $\mathbf{n}$ & $\%$ & $\mathbf{n}$ & $\%$ & $\mathrm{n}$ & $\%$ & $\mathrm{n}$ & $\%$ & $\mathbf{n}$ & $\%$ & \\
\hline 491.0 - Simple chronic bronchitis & 221 & $12.1 \%$ & 473 & $26.0 \%$ & 512 & $28.1 \%$ & 395 & $21.7 \%$ & 220 & $12.1 \%$ & 1821 \\
\hline 491.1 - Mucopurulent chronic bronchitis & 386 & $10.6 \%$ & 957 & $26.3 \%$ & 1194 & $32.8 \%$ & 780 & $21.4 \%$ & 321 & $8.8 \%$ & 3638 \\
\hline $\begin{array}{l}491.20 \text { - Obstructive chronic bronchitis } \\
\text { without mention of acute exacerbation }\end{array}$ & 3429 & $10.3 \%$ & 8336 & $25.1 \%$ & 9842 & $29.6 \%$ & 8173 & $24.6 \%$ & 3457 & $10.4 \%$ & 33237 \\
\hline $\begin{array}{l}491.21 \text { - Obstructive chronic bronchitis } \\
\text { with acute exacerbation }\end{array}$ & 4044 & $9.3 \%$ & 10165 & $23.3 \%$ & 13003 & $29.8 \%$ & 10182 & $23.3 \%$ & 6309 & $14.4 \%$ & 43703 \\
\hline 491.8 - Other chronic bronchitis & 172 & $9.4 \%$ & 483 & $26.3 \%$ & 533 & $29.0 \%$ & 431 & $23.5 \%$ & 216 & $11.8 \%$ & 1835 \\
\hline 491.9 - Unspecified chronic bronchitis & 141 & $6.1 \%$ & 442 & $19.1 \%$ & 553 & $23.9 \%$ & 797 & $34.5 \%$ & 377 & $16.3 \%$ & 2310 \\
\hline 492 - Emphysema & 122 & $11.9 \%$ & 274 & $26.7 \%$ & 311 & $30.3 \%$ & 206 & $20.0 \%$ & 115 & $11.2 \%$ & 1028 \\
\hline 493 - Asthma & 5000 & $35.1 \%$ & 4921 & $34.6 \%$ & 2429 & $17.1 \%$ & 1238 & $8.7 \%$ & 640 & $4.5 \%$ & 14228 \\
\hline 518.81 - Respiratory failure & 815 & $2.5 \%$ & 5040 & $15.2 \%$ & 9424 & $28.4 \%$ & 10183 & $30.6 \%$ & 7772 & $23.4 \%$ & 33234 \\
\hline Totals & 14330 & $10.6 \%$ & 31091 & $23.0 \%$ & 37801 & $28.0 \%$ & 32385 & $24.0 \%$ & 19427 & $14.4 \%$ & 135034 \\
\hline \multirow{2}{*}{ Principal diagnosis Day-hospital } & \multicolumn{2}{|c|}{$\mathbf{0}$} & \multicolumn{2}{|c|}{1} & \multicolumn{2}{|c|}{2} & \multicolumn{2}{|c|}{3} & \multicolumn{2}{|c|}{4 or more } & Total \\
\hline & n & $\%$ & n & $\%$ & n & $\%$ & n & $\%$ & n & $\%$ & \\
\hline 491.0 - Simple chronic bronchitis & 244 & $41.4 \%$ & 208 & $35.3 \%$ & 100 & $17.0 \%$ & 27 & $4.6 \%$ & 10 & $1.7 \%$ & 589 \\
\hline 491.1 - Mucopurulent chronic bronchitis & 30 & $33.3 \%$ & 25 & $27.8 \%$ & 22 & $24.4 \%$ & 13 & $14.4 \%$ & 0 & $0.0 \%$ & 90 \\
\hline $\begin{array}{l}491.20 \text { - Obstructive chronic bronchitis } \\
\text { without mention of acute exacerbation }\end{array}$ & 1355 & $50.7 \%$ & 717 & $26.8 \%$ & 321 & $12.0 \%$ & 211 & $7.9 \%$ & 69 & $2.6 \%$ & 2673 \\
\hline $\begin{array}{l}491.21 \text { - Obstructive chronic bronchitis } \\
\text { with acute exacerbation }\end{array}$ & 475 & $36.3 \%$ & 511 & $39.1 \%$ & 190 & $14.5 \%$ & 83 & $6.4 \%$ & 48 & $3.7 \%$ & 1307 \\
\hline 491.8 - Other chronic bronchitis & 115 & $56.9 \%$ & 50 & $24.8 \%$ & 29 & $14.4 \%$ & 7 & $3.5 \%$ & 1 & $0.5 \%$ & 202 \\
\hline 491.9 - Unspecified chronic bronchitis & 46 & $38.3 \%$ & 32 & $26.7 \%$ & 21 & $17.5 \%$ & 18 & $15.0 \%$ & 3 & $2.5 \%$ & 120 \\
\hline 492 - Emphysema & 43 & $42.2 \%$ & 32 & $31.4 \%$ & 17 & $16.7 \%$ & 9 & $8.8 \%$ & 1 & $1.0 \%$ & 102 \\
\hline 493 - Asthma & 2034 & $55.3 \%$ & 1185 & $32.2 \%$ & 351 & $9.5 \%$ & 91 & $2.5 \%$ & 18 & $0.5 \%$ & 3679 \\
\hline 518.81 - Respiratory failure & 27 & $12.4 \%$ & 57 & $26.1 \%$ & 70 & $32.1 \%$ & 46 & $21.1 \%$ & 18 & $8.3 \%$ & 218 \\
\hline Totals & 4369 & $48.7 \%$ & 2817 & $31.4 \%$ & 1121 & $12.5 \%$ & 505 & $5.6 \%$ & 168 & $1.9 \%$ & 898 \\
\hline
\end{tabular}

diological diagnoses are often associated with chronic respiratory diseases, and hypertensive cardiopathy is indicated in $7.4 \%$ of the cases of COPD without acute exacerbation and $9.7 \%$ of COPD with acute exacerbation. For arterial hypertension the relative figures are $9.3 \%$ and $7.6 \%$. The first 14 secondary diagnoses explain over $50 \%$ of the comorbities indicated in the records. In dayhospital hypertensive cardiopathy is most frequently associated with the diagnosis of COPD with and without acute exacerbation.

Spirometry and arterial blood gas analysis (ABG) (table 8) are the procedures most frequently shown on the discharge records of those patients affected by obstructive pulmonary diseases. For in-patients $3.2 \%$ and $7.7 \%$ respectively and for day-hospital $18.3 \%$ and $12.0 \%$ respectively.

For in-patients the principal diagnoses more frequently associated with hemogasanalysis were COPD without acute exacerbation, mucopurulent chronic bronchitis and emphysema. Spirometry is indicated in only $6.6 \%$ of the discharge records for COPD without acute exacerbation and in $7.0 \%$ of those for simple chronic bronchitis.

These two procedures are more common in day-hospital. Those with respiratory failure as a principal diagnosis had ABG in $29.3 \%$ of cases and for COPD with acute exacerbation the procedure was carried out in $21.4 \%$ of cases. Spirometry was more often associated with emphysema, $22.0 \%$ and asthma, 22.7\%. For cases of COPD it was carried out in $15.3 \%$ of cases of the acute form and $16.8 \%$ of cases of COPD without acute exacerbation.

\section{Discussion}

COPD is one of the most widespread diseases in the world and it has the highest direct costs to the health system. For chronic diseases it is also the disease more frequently associated, in the case of hospitalisation, with a high comorbidity and 


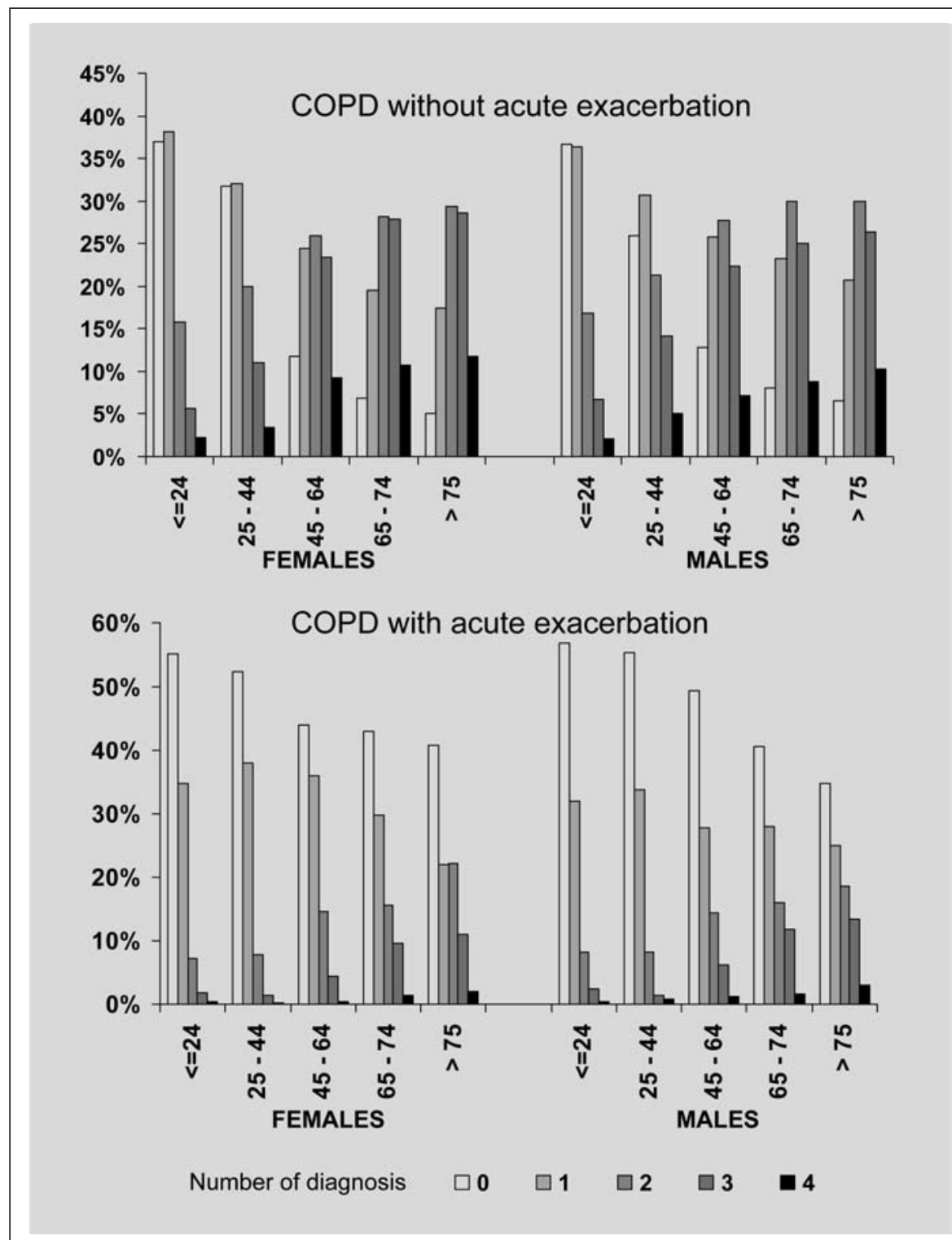

Fig. 6. - Distribution of admissions with a diagnosis of chronic respiratory disease in principal diagnosis in relation to the number of secondary diagnoses reported on the discharge record and age range.

of chronic diseases without recourse to hospitalisation. Although it is possible that a result has been obtained in the reduction of admissions in the age group 45-65, without however producing a useful effect on the older age groups.

In the American health system it was believed possible to obtain a reduction in hospitalisation for chronic respiratory diseases, including COPD, thanks to changes in health policies such as the introduction of DRG for financing and pressure on the system to reduce hospital use. These actions however produced only a more efficient use of the hospitals, they were not able, in the case of chronic respiratory disorders, to reduce the number of hospitalisations that have actually increased from 1995, with a relative increase in mortality [20].

The problem of managing chronic disorders in old age does not benefit from policies alone aimed at improving efficiency, but must be addressed in a more complex way, with more integration between the resources available for the hospital and those available for care in the community [18]. Specific studies could allow the identification of avoidable

mortality. Its high comorbidity makes it difficult to evaluate the costs of COPD care [18].

The data obtained from this analysis allows us to hypothesise that Chronic Obstructive Pulmonary Disease has a high incidence in so far as it was found in more than 81,000 subjects in the period 2000-2005 (table 3), who represent only a part of the cases of COPD in the Puglian Territory to whom must be added those who are not treated in hospital. This hypothesis is supported by the fact that in-patients are older than those treated as dayhospital and by the fact that the disease can arise in a young age and require hospital treatment. It is however its clinical complexity and the presence of comorbidity in the older patients which principally determines the high cost of the management of the disease.

The hospitalisation rate for over 65's with COPD is particularly high. There could be many reasons for this, on the one hand there is the normal increase in care costs for older people with chronic diseases, but on the other hand there is the lack of complete programmes for the management hospital admissions which are now necessary owing to the lack of other viable care.

Also in Italy, health policies geared towards efficiency have produced a reduction in hospital admissions but they have not fostered a reduction in admissions for COPD and respiratory failure as demonstrated not only by the information here present but also by the statistics of the Italian Ministry of Health on hospital admissions. In fact there is a progressive increase in nationwide admissions for COPD with acute exacerbation (from 102,297 del 2000 to 188,562 in 2004) and respiratory failure (from 49,314 in 2000 to 187,660 in 2004) [21]. Even if this large increase shown here and in the national data could be due to an improvement in the description of the cases caused by the codes ICD9-CM, which allow the distinction between COPD with (code 491.20). and without (code 491.21) acute exacerbation. A confirmation of this hypothesis is in the downward trend of nationwide admissions for COPD without acute exacerbation from 248,539 cases in 1999 to 162,170 in 2000 and 53,034 in 2004. 
Table 6. - Distribution of secondary diagnoses in relation to the principal diagnosis reported on the discharge records. In-patients

\begin{tabular}{|c|c|c|c|c|c|c|c|c|}
\hline \multirow[t]{2}{*}{ Diagnosis } & \multicolumn{2}{|c|}{$\begin{array}{l}491.20 \text { - Obstructive } \\
\text { chronic bronchitis } \\
\text { without mention } \\
\text { f acute exacerbation }\end{array}$} & \multicolumn{2}{|c|}{$\begin{array}{l}491.21 \text { - Obstructive } \\
\text { chronic bronchitis } \\
\text { with acute } \\
\text { exacerbation }\end{array}$} & \multicolumn{2}{|c|}{$\begin{array}{l}518.81 \text { - Respiratory } \\
\text { failure }\end{array}$} & \multicolumn{2}{|c|}{ Totals } \\
\hline & $\mathbf{N}^{\circ}$ & $\%$ & $\mathbf{N}^{\circ}$ & $\%$ & $\mathbf{N}^{\circ}$ & $\%$ & $\mathbf{N}^{\circ}$ & $\%$ \\
\hline 491 - Chronic bronchitis & 3385 & $5.0 \%$ & 3384 & $3.6 \%$ & 16651 & $18.8 \%$ & 24648 & $8.5 \%$ \\
\hline 402 - Hypertensive heart disease & 5013 & $7.4 \%$ & 9148 & $9.7 \%$ & 4689 & $5.3 \%$ & 20733 & $7.2 \%$ \\
\hline 401 - Essential hypertension & 6324 & $9.3 \%$ & 7170 & $7.6 \%$ & 3635 & $4.1 \%$ & 19930 & $6.9 \%$ \\
\hline 250 - Diabetes mellitus & 5244 & $7.7 \%$ & 7027 & $7.5 \%$ & 5214 & $5.9 \%$ & 19632 & $6.8 \%$ \\
\hline 414 - Ischemic heart disease & 4628 & $6.8 \%$ & 6303 & $6.7 \%$ & 4298 & $4.9 \%$ & 16966 & $5.9 \%$ \\
\hline 427 - Cardiac dysrhytmias & 2568 & $3.8 \%$ & 4271 & $4.5 \%$ & 3584 & $4.1 \%$ & 11388 & $3.9 \%$ \\
\hline 278 - Obesity and other hyperalimentation & 1524 & $2.3 \%$ & 1980 & $2.1 \%$ & 2436 & $2.8 \%$ & 7006 & $2.4 \%$ \\
\hline 416 - Chronic pulmonary heart disease & 1754 & $2.6 \%$ & 1607 & $1.7 \%$ & 2986 & $3.4 \%$ & 6720 & $2.3 \%$ \\
\hline 571 - Chronic liver disease and cirrhosis & 1867 & $2.8 \%$ & 2760 & $2.9 \%$ & 938 & $1.1 \%$ & 6503 & $2.3 \%$ \\
\hline 518 - Other diseases of lung & 1617 & $2.4 \%$ & 2825 & $3.0 \%$ & 1167 & $1.3 \%$ & 6346 & $2.2 \%$ \\
\hline $\begin{array}{l}429 \text { - Ill-defined descriptions and complications } \\
\text { of heart disease }\end{array}$ & 1988 & $2.9 \%$ & 2092 & $2.2 \%$ & 1506 & $1.7 \%$ & 6297 & $2.2 \%$ \\
\hline 428 - Heart failure & 835 & $1.2 \%$ & 1251 & $1.3 \%$ & 2305 & $2.6 \%$ & 4686 & $1.6 \%$ \\
\hline 780 - general symptoms (syncope) & 590 & $0.9 \%$ & 705 & $0.7 \%$ & 2662 & $3.0 \%$ & 4250 & $1.5 \%$ \\
\hline 585 - Chronic renal failure & 827 & $1.2 \%$ & 1706 & $1.8 \%$ & 1159 & $1.3 \%$ & 4021 & $1.4 \%$ \\
\hline Others & 29539 & $43.6 \%$ & 41982 & $44.6 \%$ & 35243 & $39.8 \%$ & 129686 & $44.9 \%$ \\
\hline Totals & 67703 & $100.0 \%$ & 94211 & $100.0 \%$ & 88473 & $100.0 \%$ & 288812 & $100.0 \%$ \\
\hline
\end{tabular}

Table 7. - Distribution of secondary diagnoses in relation to the principal diagnosis reported on the discharge records. Day-hospital

\begin{tabular}{|c|c|c|c|c|c|c|c|c|}
\hline \multirow[t]{2}{*}{ Diagnosis } & \multicolumn{2}{|c|}{$\begin{array}{l}491.20 \text { - Obstructive } \\
\text { chronic bronchitis } \\
\text { without mention } \\
\text { f acute exacerbation }\end{array}$} & \multicolumn{2}{|c|}{$\begin{array}{l}\text { 491.21 - Obstructive } \\
\text { chronic bronchitis } \\
\text { with acute } \\
\text { exacerbation }\end{array}$} & \multicolumn{2}{|c|}{$\begin{array}{l}518.81 \text { - Respiratory } \\
\text { failure }\end{array}$} & \multicolumn{2}{|c|}{ Totals } \\
\hline & $\mathbf{N}^{\circ}$ & $\%$ & $\mathbf{N}^{\circ}$ & $\%$ & $\mathbf{N}^{\circ}$ & $\%$ & $\mathbf{N}^{\circ}$ & $\%$ \\
\hline 491 - Chronic bronchitis & 142 & $6.1 \%$ & 161 & $11.9 \%$ & 18 & $4.4 \%$ & 321 & $7.9 \%$ \\
\hline 402 - Hypertensive heart disease & 201 & $8.7 \%$ & 66 & $4.9 \%$ & 22 & $5.4 \%$ & 289 & $7.1 \%$ \\
\hline 401 - Essential hypertension & 152 & $6.6 \%$ & 95 & $7.0 \%$ & 3 & $0.7 \%$ & 250 & $6.1 \%$ \\
\hline 250 - Diabetes mellitus & 110 & $4.8 \%$ & 83 & $6.1 \%$ & 24 & $5.9 \%$ & 217 & $5.3 \%$ \\
\hline 414 - Ischemic heart disease & 119 & $5.1 \%$ & 57 & $4.2 \%$ & 23 & $5.6 \%$ & 199 & $4.9 \%$ \\
\hline 427 - Cardiac dysrhytmias & 5 & $0.2 \%$ & 185 & $13.7 \%$ & & $0.0 \%$ & 190 & $4.7 \%$ \\
\hline 278 - Obesity and other hyperalimentation & 139 & $6.0 \%$ & 26 & $1.9 \%$ & 7 & $1.7 \%$ & 172 & $4.2 \%$ \\
\hline 416 - Chronic pulmonary heart disease & 16 & $0.7 \%$ & 2 & $0.1 \%$ & 115 & $28.2 \%$ & 133 & $3.3 \%$ \\
\hline 571 - Chronic liver disease and cirrhosis & 58 & $2.5 \%$ & 25 & $1.8 \%$ & 28 & $6.9 \%$ & 111 & $2.7 \%$ \\
\hline 518 - Other diseases of lung & 84 & $3.6 \%$ & 24 & $1.8 \%$ & 1 & $0.2 \%$ & 109 & $2.7 \%$ \\
\hline $\begin{array}{l}429 \text { - Ill-defined descriptions and complications } \\
\text { of heart disease }\end{array}$ & 52 & $2.3 \%$ & 21 & $1.6 \%$ & 5 & $1.2 \%$ & 78 & $1.9 \%$ \\
\hline 428 - Heart failure & 48 & $2.1 \%$ & 12 & $0.9 \%$ & 11 & $2.7 \%$ & 71 & $1.7 \%$ \\
\hline 780 - general symptoms (syncope) & 21 & $0.9 \%$ & 46 & $3.4 \%$ & 2 & $0.5 \%$ & 69 & $1.7 \%$ \\
\hline 585 - Chronic renal failure & 42 & $1.8 \%$ & 25 & $1.8 \%$ & 1 & $0.2 \%$ & 68 & $1.7 \%$ \\
\hline Others & 1122 & $48.6 \%$ & 525 & $38.8 \%$ & 148 & $36.3 \%$ & 1795 & $44.1 \%$ \\
\hline Totals & 2311 & $100.0 \%$ & 1353 & $100.0 \%$ & 408 & $100.0 \%$ & 4072 & $100.0 \%$ \\
\hline
\end{tabular}


Table 8. - Diagnostic procedure reported on the discharge database with a principal diagnosis of Chronic Obstructive Pulmonary Disease or respiratory failure

\begin{tabular}{|c|c|c|c|c|c|c|c|c|c|c|}
\hline \multirow{3}{*}{ Diagnosis } & \multicolumn{5}{|c|}{ In-patients } & \multicolumn{5}{|c|}{ Day-hospital } \\
\hline & \multirow{2}{*}{$\begin{array}{c}\text { Total } N^{\circ} \\
\text { discharge } \\
\text { records }\end{array}$} & \multicolumn{2}{|c|}{ Spirometry } & \multicolumn{2}{|c|}{$\mathrm{ABG}$} & \multirow{2}{*}{$\begin{array}{c}\text { Total } N^{\circ} \\
\text { discharge } \\
\text { records }\end{array}$} & \multicolumn{2}{|c|}{ Spirometry } & \multicolumn{2}{|c|}{$\mathrm{ABG}$} \\
\hline & & $\mathbf{n}^{\circ}$ & $\%$ & $\mathbf{n}^{\circ}$ & $\%$ & & $\mathbf{n}^{\circ}$ & $\%$ & $\mathbf{n}^{\circ}$ & $\%$ \\
\hline 491.0 - Simple chronic bronchitis & 1505 & 106 & $7.0 \%$ & 129 & $8.6 \%$ & 591 & 81 & $13.7 \%$ & 70 & $11.8 \%$ \\
\hline 491.1 - Mucopurulent chronic bronchitis & 2698 & 164 & $6.1 \%$ & 464 & $17.2 \%$ & 89 & 9 & $10.1 \%$ & 14 & $15.7 \%$ \\
\hline $\begin{array}{l}491.20 \text { - Obstructive chronic bronchitis } \\
\text { without mention of acute exacerbation }\end{array}$ & 23723 & 1555 & $6.6 \%$ & 3257 & $13.7 \%$ & 2626 & 440 & $16.8 \%$ & 378 & $14.4 \%$ \\
\hline $\begin{array}{l}491.21 \text { - Obstructive chronic bronchitis } \\
\text { with acute exacerbation }\end{array}$ & 50409 & 1037 & $2.1 \%$ & 2618 & $5.2 \%$ & 1362 & 209 & $15.3 \%$ & 291 & $21.4 \%$ \\
\hline 491.8 - Other chronic bronchitis & 1187 & 55 & $4.6 \%$ & 129 & $10.9 \%$ & 190 & 18 & $9.5 \%$ & 12 & $6.3 \%$ \\
\hline 491.9 - Uspecified chronic bronchitis & 2121 & 24 & $1.1 \%$ & 59 & $2.8 \%$ & 113 & 2 & $1.8 \%$ & 3 & $2.7 \%$ \\
\hline 492 - Emphysema & 955 & 44 & $4.6 \%$ & 149 & $15.6 \%$ & 109 & 24 & $22.0 \%$ & 24 & $22.0 \%$ \\
\hline 493 - Asthma & 13888 & 774 & $5.6 \%$ & 500 & $3.6 \%$ & 3671 & 832 & $22.7 \%$ & 221 & $6.0 \%$ \\
\hline 518.81 - Respiratory failure & 38548 & 573 & $1.5 \%$ & 3040 & $7.9 \%$ & 229 & 29 & $12.7 \%$ & 67 & $29.3 \%$ \\
\hline Total & 135034 & 4332 & $3.2 \%$ & 10345 & $7.7 \%$ & 8980 & 1644 & $18.3 \%$ & 1080 & $12.0 \%$ \\
\hline
\end{tabular}

However the upward trend in the hospitalisation rate for COPD with and without acute exacerbation is increasing over time. The modifications in hospital management such as payment for performance and the encouragement of out-patient treatment have led to more efficiency, obtained as a result of increasing performance without increasing resources and through, in the case of in-patients, reducing the number of bed occupancy days, with the risk of causing a readmission, above all in cases of chronic illnesses.

This could lead to an increase in admissions for some cases which would explain the increase in the hospitalisation rate, even if we cannot completely exclude that the increase could be linked to a increase in the incidence of the disease in the territory.

The use of management and health databases, with particular reference to the discharge database, is a limitation both due to the necessity for a correct definition of a case and because of observational bias. According to Mannino $[18,20]$ the choice of the codes to define a case can lead to very different conclusions on the incidence and prevalence for age and sex. In fact to include diagnoses of emphysema and chronic bronchitis in the analysis of chronic respiratory diseases can lead to a high prevalence among young people with respect to older people. He also affirms that the use of spirometry for screening could improve the quality of determining incidence and prevalence. The appropriate diagnosis should be based on an objective reduction of $\mathrm{FEV}_{1}$, but often the discharge record does not hold the details to should show that the diagnostic procedure has been carried out, meaning that any estimate of COPD would be unreliable if based of diagnostic procedures. We could perhaps think that the diagnosis was based only on the clinical aspects without the use of instrument based diagnostic procedures. In any case the discharge database does not permit the recording of the outcome of the spirometry. The possibility of ascertaining the gravity of the disease would allow a more precise care/cost estimate insomuch as the more serious cases, which use more resources, could be better evaluated. Administrative databases are inadequate in evaluating the distribution of the gravity of the disease so the socio-economic cost of a disease could be under or over estimated.

As with many other hospital statistics the number of admissions for males is higher than that of females. This data is different to that seen in other countries (e.g. USA). Through the use of questionnaires to determine the prevalence of COPD among the public based on their replies, from 1987 the questionnaires have shown that the rate of incidence of the disease is higher among females than among males, and that in the period 1980-96 the rate has not varied in males but that there is an upward trend for females. The NHANES studies, based on spirometry examinations, have shown that the prevalence rate among women has progressively grown and that increasing age increases the rate for both males and females [20].

One of the causes for this increase in females could be explained by an increased exposure to risk factors, for example smoking has increased among women, though it has not yet reached the level seen in men. Although smoking is a major risk factor, it is still difficult to determine what weight to give to the reduction in smoking in general and what to give to the occupational and environmental factors that seem to play a negative role especially in countries of low and medium socioeconomic status. Currently there is evidence to 
show that the improvement of these conditions has reduced the frequency of acute respiratory infections that can act as predisposing factors for the development of chronic respiratory diseases [18].

The geographic distribution, different between rural areas, high population density cities with industry and towns distant from industrial areas, can be correlated to aetiopathogenetic causes, insofar as they suggest the responsibility of environmental factors in influencing the frequency of the disease and consequently a greater need for hospitalisation. The higher rate of hospitalisation in cities and their surrounding areas could be explained either by the easier access to hospitals and to more specialised care, or by the role played by the environmental pollutants in the onset and development of the disease. Those pollutants studied most are the combustion oxides and particulate matter that have a role not only outdoor but also indoor due to contamination from outside and production at home and at work [22-28].

The repeated admissions are an important factor in the costs of the National Health Service and a more detailed analysis could bring out ideas to better manage the costs [29]. From a superficial analysis of the tables herein it could be concluded that the diagnosis of COPD without acute exacerbation leads to re-admission in that $40 \%$ of the patients have at least two admissions (in-patients and day hospital together). The analysis of re-admission reveals that, at least in the period under examination, the reason for the re-admission is generally the same as the previous admission (i.e. same diagnosis) and so there is no worsening of the condition that could justify the re-admission. In these cases it is important to investigate how it would be possible to avoid such re-admissions, or one must presume that still today 10 years after the introduction of the discharge database and the diagnosis codes, there is an inappropriate use of the ICD9-CM codes.

An aspect worthy of comment is the elevated percentage of re-admission for patients affected by respiratory failure at first admission. This is what shows that the most advanced phase of the disease takes the most resources. It should be considered that the frequency of repeated admissions could be controlled by improving the patient compliance to treatment, experimenting with alternatives to inpatient treatment and reinforcing out-patient services.

An assessment of the periodicity of the acute exacerbations could perhaps show an association between admissions with a principal diagnosis of respiratory failure or COPD with acute exacerbation any previous admissions with other acute diseases of the respiratory system (influenza, bronchitis, pneumonia, etc.) [30-32].

The acute exacerbations greatly impact the quality of life of the patient and the evolution of the disease. They also create the need for frequent care [33].

They can appear in many different forms and seriousness from slight and fleeting worsening of symptoms, managed directly by an aware patient, to very serious conditions which require hospitalisation in intensive care [34]. The reasons for admission are numerous and must be evaluated individually for each case [35].

Kinnunen has shown that the rate hospitalisation in advanced age is rather high and that the more serious cases, followed by death within the year, show frequent periods in hospital in the last months of life [36]. The advanced age of the patient, as seen in this study and numerous others, helps explain the high frequency of acute exacerbations and repeated need for hospital care; the comorbidities shown in the Puglia discharge records allow us to define the patient's compromising clinical picture, the seriousness of the prognosis and the need for a higher costly level of care for patients in advanced age.

The decision of whether to admit a patient with COPD with acute exacerbation can significantly influence both the prognosis and the quality of life of the patient. It is however extremely difficult to define guidelines for what to do as the decision is strongly influenced not only by the clinical condition of the patient but also by the financial resources of both the family and the hospital [37].

In any case the decision as to whether to go into hospital or not is, today, a great problem from both a socio-political and management viewpoint [38].

The availability of epidemiological data must be, for the disease under consideration, the only factor that should be considered when deciding on regional health policies, the distribution of resources, the organisational structure and the giving of care. Chronic respiratory disease can also become an example for the application of innovative management models based on a just integration between the hospital and the community geared towards the activation of home care plans and the organisation long-stay wards. The choices, shown in Health Plans, should be the base for coherent and uniform action regionally and nationally with the objective to reduce the social-health impact of the disease and produce the maximum benefit for the patients.

\section{References}

1. Minino AM, Heron MP Murphy SL, et al. Deaths: final data for 2004. NVSR, 2007, 55 (19): 1.

2. Capitolo 3. Sanità e Salute, in Annuario Statistico Italiano 2006, ISTAT, Roma, 2006.

3. Murray CJ Lopez AD Alternative projections of mortality and disability by cause 1990-2020: Global Burden of Disease Study. The Lancet 1997; 349: 1498-1504.

4. Sabbadini LL, Gargiulo L, Sebastiani G. Condizioni di salute, fattori di rischio e ricorso ai servizi sanitari. Anno 2005. ISTAT, Nota per la stampa, marzo 2007, pagg. 1-55.

5. Rapporto Annuale Sull'Attività di Ricovero Ospedaliero-Dati SDO 2003, Ministero della Salute, Area Editoriale, Roma, 2006.

6. Meulepas MA, Jacobs JE, Lucas AEM, et al. The feasibility of a primary care model for the management of COPD. Prim Care Resp J 2006; 15: 337-41.

7. Casas A, Troosters T, Garcia-Aymerich J, et al. Integrated care prevents hospitalisations for exacerbations in COPD patients. Eur Respir J 2006; 28: 123-130.

8. Kanner RE, Anthonisen, NR, Connett JE. Lower respiratory illnesses promote FEV1 decline in current smokers but not exsmokers with mild chronic obstructive lung disease: results 
from the Lung Health Study. Am J Respir Crit Care Med 2001; 164: $358-64$

9. Donaldson GC, Seemungal TAR, Bhowmik A, Wedzicha JA. The relationship between exacerbation frequency and lung function decline in chronic obstructive pulmonary disease. Thorax 2002: 57: 847-52.

10. Soler-Cataluna JJ, Martinez-Garcia MA, Roman Sanchez P, Salcedo E, Navarro M, Ochando R. Severe acute exacerbations and mortality in patients with chronic obstructive pulmonary disease. Thorax 2005; 60: 925-931.

11. Garcia-Aymerich, Farrero E, Félez MA, Izquierdo J, Marrades RM, Antó JM. Risk factors of readmission to hospital for a COPD exacerbation: a prospective study. Thorax 2003; 58: 100-105.

12. Holland R, Lenaghan E, Harvey I, et al. Does home based medication people out of hospital? The HOMER randomised controlled trial. BMJ 2005; 330: 293.

13. Hermiz O, Comino E, Marks G, et al. Randomised controlled trial of home based care of patients with chronic obstructive pulmonary disease. $B M J$ 2002; 325: 938.

14. Alonso A. A new model for home care for CODP. Stud Health Technol Inform 2004; 103: 368-73.

15. Puig-Junoy J, Casas A, Font-Planells J, et al. The impact of home hospitalization on healthcare costs of exacerbations in COPD patients. Eur J Health Econ 2007; 8: 325-332.

16. Richard A, Mularski, Asch SM, Shrank WA, et al. The Quality of Obstructive Lung Disease Care for Adults in the United States as Measured by Adherence to Recommended Processes. Chest 2006; 130: 1844-1850.

17. Hoskera H, Ansteyb K, Loweb D, et al. Variability in the organisation and management of hospital care for COPD exacerbations in the UK. Respir Med 2007; 101: 754-761.

18. Mannino DM, Buist AS. Global burden of COPD: risk factors, prevalence, and future trends, Lancet 2007; 370: 765-73.

19. Ministero della Salute, Piano Sanitario Nazionale 2006-2008, Capitolo 5 Gli obiettivi di salute del Servizio Sanitario Nazionale, 2006, Roma, http: //www.ministerosalute.it/resources/static/primopiano/316/capitolo 5.pdf.

20. Mannino DM, Homa DM, Akinabami LJ, et al. Chronic obstructive pulmonary disease surveillance-United States, 1971200, MMWR, 2002, 51/ss06, 1-16.

21. Rapporti annuali sui ricoveri ospedalieri, anno 2003. www.ministerosalute.it/programmazione/sdo.

22. Liu S, Zhou Y, Wang X, et al. Biomass fuels are the probable risk factor for chronic obstructive pulmonary disease in rural South China. Thorax 2007; 62: 889-97. Epub 2007 May 4.

23. Ko FW, Tam W, Wong TW, et al. Temporal relationship between air pollutants and hospital admissions for chronic obstructive pulmonary disease in Hong Kong. Thorax 2007; 62: 780-5. Epub 2007 Feb 20.
24. Viegi G, Maio S, Pistelli F, Baldacci S, Carrozzi L. Epidemiology of chronic obstructive pulmonary disease: health effects of air pollution. Respirology 2006; 11: 523-32.

25. Medina-Ramón M, Zanobetti A, Schwartz J. The effect of ozone and PM10 on hospital admissions for pneumonia and chronic obstructive pulmonary disease: a national multicity study. Am J Epidemiol 2006; 163: 579-88. Epub 2006 Jan 27.

26. Yang Q, Chen Y, Krewski D, Burnett RT, Shi Y, McGrail KM Effect of short-term exposure to low levels of gaseous pollutants on chronic obstructive pulmonary disease hospitalizations. Environ Res 2005; 99: 99-105. Epub 2004 Nov 21.

27. Moolgavkar SH. Air pollution and hospital admissions for chronic obstructive pulmonary disease in three metropolitan areas in the United States. Inhal Toxicol 2000; 12 Suppl 4: 75-90.

28. Rossi G, Vigotti MA, Zanobetti A, Repetto F, Gianelle V, Schwartz J. Air pollution and cause-specific mortality in Milan, Italy, 1980-1989. Arch Environ Health 1999; 54: 158-64.

29. Halfon P, Eggli Y, Pretre-Rohrbach I, Meylan D, Marazzi A, Burnand B. Validation of the potentially avoidable hospital readmission rate as a routine indicator of the quality of hospital care. Med Care 2006; 44: 972-81.

30. Burge PS. Prevention of exacerbations: how are we doing and can we do better? Proc Am Thorac Soc 2006; 3: 257-61.

31. Bhowmik A, Seemungal TA, Donaldson GC, Wedzicha JA. Effects of exacerbations and seasonality on exhaled nitric oxide in COPD. Eur Respir J 2005; 26: 1009-15.

32. Yap FH, Ho PL, Lam KF, Chan PK, Cheng YH, Peiris JS. Excess hospital admissions for pneumonia, chronic obstructive pulmonary disease, and heart failure during influenza seasons in Hong Kong. J Med Virol 2004; 73: 617-23.

33. Llor C, Molina J, Naberan K, Cots JM, Ros F, Miravitlles M; the EVOCA study group. Exacerbations worsen the quality of life of chronic obstructive pulmonary disease patients in primary healthcare. Int J Clin Pract 2008 Feb 7 [Epub ahead of print].

34. Silverman EK. Exacerbations in chronic obstructive pulmonary disease: do they contribute to disease progression? Proc Am Thorac Soc 2007; 4: 586-90.

35. Hilleman DE, Dewan N, Malesker M, Friedman M. Pharmacoeconomic evaluation of COPD. Chest 2000; 118: 1278-85.

36. Kinnunen T. Saynajakagas O, Keistinen T, The CODP-induced hospitalization burden from first admission to death. Respiratory Medicine 2007, 101: 294-299.

37. Miravitlles M, Murio C, Guerrero T, Gisbert R. Pharmacoeconomic evaluation of acute exacerbations of chronic bronchitis and COPD. Chest 2002; 121: 1449-55.

38. Trakada G, Spiropoulos K. Chronic obstructive pulmonary disease management among primary healthcare physicians. Monaldi Arch Chest Dis. 2000; 55: 201-4.

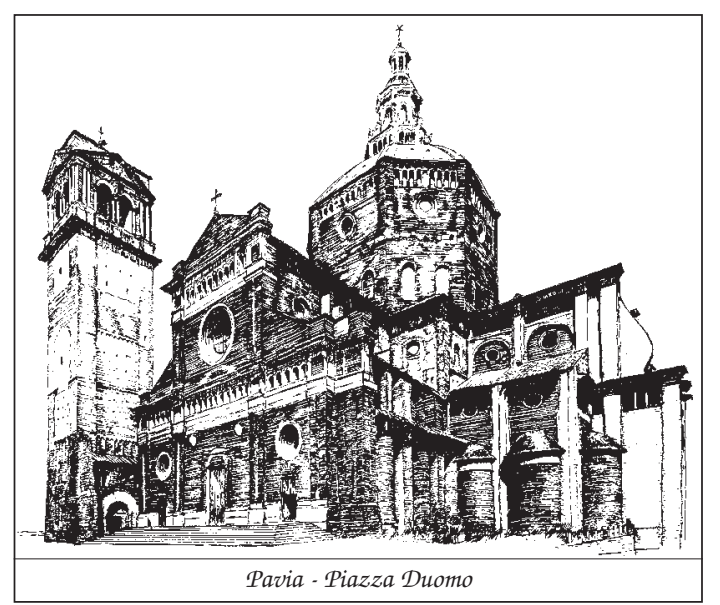

